\title{
Intoxicação por Senna occidentalis (Leg. Caesalpinoideae) em bovinos em pastoreio ${ }^{1}$
}

\author{
Claudio S.L. Barros ${ }^{2}$, Márcia Regina Silva Ilha ${ }^{3}$, Pedro Soares Bezerra Junior ${ }^{4}$, \\ Ingeborg Maria Langohr ${ }^{5}$ e Glaucia Denise Kommers ${ }^{2}$
}

\begin{abstract}
Barros C.S.L., Ilha M.R.S., Bezerra Jr. P.S., Langhor I.M. \& Kommers G.D. 1999. [Poisoning by Senna occidentalis (Leg. Caesalpinoideae) in grazing cattle.] Intoxicação por Senna occidentalis (Leg. Caesalpinoideae) em bovinos em pastoreio. Pesquisa Veterinária Brasileira 19(2):68-70. Depto Patologia, Universidade Federal de Santa Maria, 97105-900 Santa Maria, RS, Brazil.

Three outbreaks of Senna occidentalis poisoning in cattle exclusively at pasture are described. The outbreaks occurred in the fall and early winter on three farms of the state of Rio Grande do Sul, Brazil. Affected cattle had access to pastures previously used as culture fields for soybean and corn, which were heavily infested by coffee senna (S. occidentalis). On farm 1, 10 $(29,1 \%)$ out of a total of 34 about 18-month-old heifers died; on farm 2, $9(4,2 \%)$ out of 212 pregnant cows died, and on farm $3,36(12,0 \%)$ out of 50 adult cattle died. Clinical courses varied from 3 to 6 days, and clinical signs included dark urine, muscle weakness, tremors, staggering gait, sternal recumbency and death. Even when in recumbency, affected cattle remained alert and with normal reflexes; they drunk water and kept their appetite until few hours before death. On farm 2, clinical signs appeared 7 days after the animals had been removed from the coffee senna infested fields. The main gross pathological findings were pale areas in the skeletal muscles, mainly in the heavy muscles of the hindlimbs, and pale yellowish streaks in the myocardium. The main histopathological finding was necrosis of skeletal muscles (multifocal and multiphasic toxic degenerative myopathy). The diagnosis of $S$. occidentalis poisoning in these three outbreaks was based on the epidemiological and clinical data, the necropsy and histopathological findings.
\end{abstract}

INDEX TERMS: Poisonous plants, Senna occidentalis, Cassia occidentalis, Leguminosae Caesalpinoideae, diseases of cattle, pathology, myopathy.

RESUMO.- São descritos três surtos da intoxicação por Senna occidentalis em bovinos em criação extensiva, exclusivamente em pastoreio, durante o outono e início do inverno, em três estabelecimentos do estado do Rio Grande do Sul. Os bovinos afetados tinham acesso a antigas lavouras de soja ou restevas de lavouras de soja e milho altamente infestados por fedegoso (S. occidentalis). No estabelecimento 1 , de um total de 34 novilhas (de aprox. 18 meses de idade), 10 morre-

\footnotetext{
${ }^{1}$ Aceito para publicação em 26 de junho de 1998.

${ }^{2}$ Departamento de Patologia, Universidade Federal de Santa Maria (UFSM), 97105-900 Santa Maria, Rio Grande do Sul.

${ }^{3}$ Estagiária do Departamento de Patologia da UFSM; bolsista de Iniciação Científica do CNPq.

${ }^{4}$ Curso de Pós-Graduação em Medicina Veterinária, Área de Patologia, UFSM.

${ }^{5}$ Estagiária do Departamento de Patologia da UFSM; bolsista de Iniciação Científica do PIBIC/CNPq.
}

ram (29,1\%); no estabelecimento 2 , morreram $9(4,2 \%)$ de um total de 212 vacas prenhes e, no estabelecimento 3 , morreram $6(12,0 \%)$ de um total de 50 animais. 0 curso clínico variou de 3 a 6 dias, e os sinais clínicos incluíam urina marromescura, fraqueza muscular, tremores, andar cambaleante, decúbito esternal e morte. Os animais, mesmo em decúbito, permaneciam alerta e com reflexos normais, alimentando-se e bebendo água até poucas horas antes da morte. No estabelecimento 2, os bovinos começaram a adoecer 7 dias após terem sido retirados do campo infestado pela planta. As principais alterações observadas na necropsia foram áreas claras na musculatura esquelética, principalmente nos músculos dos membros posteriores e estrias esbranquiçadas na musculatura cardíaca. A principal lesão microscópica era de degeneração e necrose nos músculos esqueléticos (miopatia degenerativa tóxica multifocal multifásica). Os dados epidemiológicos, clínicos, de necropsia e histopatológico 
permitiram concluir pelo diagnóstico de intoxicação por $S$. occidentalis, nesses três surtos.

TERMOS DE INDEXAÇÃO: Plantas tóxicas, Senna occidentalis, Cassia occidentalis, Leguminosae Caesalpinoideae, doenças de bovinos, patologia, miopatia.

\section{INTRODUÇÃO}

A ingestão de Senna occidentalis causa miopatia e cardiomiopatia degenerativas em suínos, bovinos, equinos (Martins et al. 1986, Barros et al. 1990, Barth et al. 1994). A planta é uma leguminosa anual encontrada em pastagens, ao longo de beira de estradas ou como invasora de lavouras. Em bovinos, a intoxicação ocorre geralmente no final do outono ou entrada do inverno, sob a forma de surtos afetando de 10 a $60 \%$ do rebanho (Barros 1993). O quadro clínico em bovinos é caracterizado por uma doença afebril, que cursa com diarréia, fraqueza muscular, ataxia e mioglobinúria. $\mathrm{O}$ animal entra em decúbito esternal, na maioria das vezes permanecendo alerta e conservando parcialmente o apetite, seguido de decúbito lateral e morte. Na fase final, há marcada elevação nos níveis séricos de CK e AT. Na necropsia há áreas pálidas, focais a coalescentes na musculatura esquelética e estrias claras no miocárdio. Histologicamente há vários graus de degeneração, necrose e ruptura de fibras musculares esqueléticas, associadas, algumas vezes, a processos proliferativos e regenerativos (Barros 1993). A lesão no miocárdio é menos intensa. Surtos da intoxicação por $S$. occidentalis, na região sul do Brasil, têm sido descritos apenas associados à ingestão de ração contaminada por sementes da planta (Martins et al. 1986, Barros et al. 1990, Barth et al. 1994). Descrevem-se aqui três surtos de intoxicação por $S$. occidentalis em bovinos em criação extensiva, exclusivamente em pastoreio, no estado do Rio Grande do Sul.

\section{MATERIAL E MÉTODOS}

Os surtos de intoxicação por Senna occidentalis L. (Link.) (nome comum: "fedegoso", anteriormente denominada Cassia occi-



Fig.1. Intoxicação espontânea por Senna occidentalis. Vaca do estabelecimento 2 que morreu poucas horas após a tomada dessa foto. Observe o estado alerta do animal, já em decúbito esternal. dentalis L.) ocorreram em três estabelecimentos. Os dados epidemiológicos e sinais clínicos foram colhidos junto aos proprietários, por visitas feitas pelos autores a dois dos estabelecimentos onde ocorreram os surtos e por informações fornecidas pelos veterinários locais. $O$ estudo macroscópico e microscópico foi realizado no material de necropsia de cinco bovinos.

\section{RESULTADOS}

\section{Estabelecimento 1}

Localizado no município de Rio Pardo, RS. Em abril de 1994, 34 novilhas estavam há 6 meses, em uma antiga lavoura de soja de 35 hectares. No momento da visita à propriedade, esse campo estava altamente infestado por Senna occidentalis. Dez novilhas $(29,1 \%)$ morreram. O curso clínico variou de 2 a 6 dias. Os sinais clínicos consistiam de urina cor de café (mioglobinúria), fezes ressequidas, relutância em mover-se, decúbito esternal e morte. Na necropsia de duas novilhas, foram observadas áreas branco-amareladas envolvendo todo um grupo muscular ou intercaladas com áreas normais. Os músculos mais afetados eram principalmente os das grandes massas musculares dos membros pélvicos e torácicos.

\section{Estabelecimento 2}

Localizado no município de São Sepé, RS. Em maio de 1997, de um total de 212 vacas prenhes, 9 adoeceram e 6 $(4,2 \%)$ morreram. Os animais permaneceram em uma resteva de lavoura de soja contaminada por $S$. occidentalis por 18 dias. Apareceram doentes a partir do sétimo dia após terem sido retirados da lavoura e introduzidos em um potreiro de campo nativo. Os sinais clínicos eram de fraqueza muscular, tremores e andar cambaleante, decúbito e morte. A evolução clínica foi de 2 a 5 dias e os animais mantinham-se alerta (Fig. 1) e se alimentando até poucas horas antes da morte. A urina tinha de cor de café (mioglobinúria). Foi realizada uma



Fig. 2. Intoxicação espontânea por S. occidentalis. Novilha do estabelecimento 1. Músculo vasto medial. Necrose flocular de duas miofibras intercaladas a miofibras normais. A miofibra necrótica ao centro da fotografia está invadida por macrófagos. A miofibra logo acima está em regeneração; observe a fileira de núcleos ao centro do miotubo. 
necropsia na propriedade, e a única alteração macroscópica observada foram áreas pálidas na musculatura esquelética dos membros posteriores.

\section{Estabelecimento 3}

Localizado no município de São Francisco de Assis, em julho de 1997. De um lote de 50 bovinos adultos da raça charolesa, 6 (12\%) morreram. Esses animais encontravam-se há 40 dias em um potreiro de campo nativo, tendo acesso à resteva de lavoura de milho infestada por $S$. occidentalis, não recebendo nenhum tipo de suplementação alimentar. A evolução clínica foi de 3 a 5 dias. Os sinais clínicos consistiram de incoordenação dos membros posteriores, urina de coloração marrom-escura, decúbito esternal e morte. Na necropsia de dois animais, observou-se bexiga contendo urina escura, cor de café. Nos músculos esqueléticos, principalmente dos membros posteriores, havia segmentos musculares pálidos. No miocárdio havia estrias branco-amareladas. Em um dos animais, as lesões eram mais intensas no ventrículo esquerdo próximo à base do coração.

As lesões histológicas foram semelhantes para todos os animais examinados. Consistiam de necrose hialina e flocular de segmentos de fibras, com ativação de células satélites e ocasional invasão de macrófagos e regeneração de miotubos (Fig. 2). No rim havia necrose e degeneração das células epiteliais dos túbulos e material homogêneo eosinofílico intratubular (nefrose hemoglobinúrica). No miocárdio de um bovino do estabelecimento 2 e de dois do estabelecimento 3 , havia discretos focos de infiltrado mononuclear associados a degeneração e necrose segmentar das fibras. No fígado de um dos bovinos do estabelecimento 2 , foram observados pequenos focos necróticos de distribuição aleatória, infiltrados por neutrófilos.

\section{DISCUSSÃO}

Nos três surtos descritos aqui, a epidemiologia, os sinais clínicos, as lesões macroscópicas e os achados histopatológicos são consistentes com o diagnóstico de intoxicação por Senna occidentalis em bovinos (Barros et al. 1990, Barros 1993, Barth et al. 1994). Os sinais clínicos são relacionados à incapacitação muscular devido à miopatia causada pela planta. A mioglobinúria, vista em cerca de $50 \%$ a $70 \%$ dos casos (Barros 1993), resulta da destruição da fibra muscular e liberação da mioglobina na circulação que posteriormente é eliminada na urina (urina marrom-avermelhada ou cor de café). Um dado clínico interessante observado nos animais deste estudo e relatado em outros surtos de intoxicação por $S$. occidentalis é que os animais podem permanecer alerta, inclusive alimentando-se e bebendo até poucas horas antes da morte (Barros 1993). Esse dado pode ser auxiliar no diagnóstico diferencial. O princípio tóxico de $S$. occidentalis não foi ainda completamente determinado.
No Brasil a intoxicação por $S$. occidentalis tem sido descrita em suínos (Martins et al. 1986) e bovinos (Barros et al. 1990, Barth et al. 1994) arraçoados e sempre associada à ingestão de ração contaminda por sementes da planta. Este trabalho indica que a intoxicação em bovinos em pastoreio pode ser também importante epidemiologicamente. A intoxicação em bovinos em pastoreio, nos EUA, ocorre geralmente em surtos afetando $10 \%$ a $60 \%$ dos animais, podendo ocorrer casos esporádicos (Pierce \& O’Hara 1967). Os índices de morbilidade nos três surtos aqui descritos foram de 4,2\%, 12 e $29,1 \%$.

Os três surtos ocorreram entre abril e junho em animais de 18 meses de idade ou mais. Dados semelhantes são relatados por outros autores (Henson et al. 1965, Pierce \& O'Hara 1967) que descrevem a intoxicação em bovinos em pastoreio nos EUA, no final do outono ou entrada do inverno, quando os pastos estão mais pobres e a planta aparentemente tornase mais palatável.

No diagnóstico diferencial, devem ser incluídas outras doenças que causam necrose muscular como deficiência de vitamina E/selênio e intoxicação por antibióticos ionóforos. $\mathrm{Na}$ intoxicação por antibióticos ionóforos em bovinos, as lesões são mais acentuadas no miocárdio e associada ao uso de ração contendo essas substâncias (Barros 1998a). Deficiência de vitamina E/selênio afeta geralmente animais jovens (2 a 4 meses) com índice elevado de crescimento e produz lesões nos músculos esqueléticos e coração que são acentuadas pela calcificação (Barros 1998b).

\section{REFERÊNCIAS}

Barros C.S.L. 1993. Intoxicações por plantas que afetam o sistema muscular. Intoxicação por Senna occidentalis, p. 201-213. In: Riet-Correa F., Méndez M.C. \& Schild A.L (ed.) Intoxicações por Plantas e Micotoxicoses em Animais Domésticos. Hemisfério Sul do Brasil, Pelotas, RS. 340 p.

Barros C.S.L. 1998a. Intoxicação por antibióticos ionóforos, p. 462-466. In: Riet-Correa F., Schild A.L. \& Méndez M.C. (ed.) Doenças de Ruminantes e Eqüinos. Editora Universitária, UFPel, Pelotas, RS. 651 p.

Barros C.S.L. 1998b. Deficiência de selênio e vitamina E, p. 528-532. In: RietCorrea F., Schild A.L. \& Méndez M.C. (ed.) Doenças de Ruminantes e Eqüinos. Editora Universitária, UFPel, Pelotas, RS. 651 p.

Barros C.S.L., Pilati C., Andujar M.B, Graça D.L., Irigoyen L.F., Lopes S.T. \& Santos C.F. 1990. Intoxicação por Cassia occidentalis (Leg. Caes.) em bovinos. Pesq. Vet. Bras. 10:47-58.

Barth A.T., Kommers G.D., Salles M.S., Wouters F. \& Barros C.S.L. 1994. Coffee senna (Senna occidentalis) poisoning in cattle. Vet. Human Toxicol. 36:541545.

Henson J.B, Dollahite JW., Bridges C.H. \& Rao R.R. 1965. Myodegeneration in cattle grazing Cassia species. J. Am. Vet. Med. Assoc. 147:142-145.

Martins E., Martins V.M.V., Riet-Correa F., Soncini R.A. \& Paraboni S.V. 1986. Intoxicação por Cassia occidentalis (Leguminosae) em suínos. Pesq. Vet. Bras. 6:35-38.

Pierce K.R. \& O'Hara P.J. 1967. Toxic myopathy in Texas cattle. Southwest. Vet. 20:179-183. 